RUNNING HEAD: Hospital Administrative Characteristics and VRM

Hospital Administrative Characteristics and Volunteer Resource Management Practices

Melissa Intindola, Ph.D.

Department of Management

Haworth College of Business

Western Michigan University

3150 Schneider Hall, Mail Stop 5429

Kalamazoo, MI 49008-5457

Tel. 812.972.5516 *

E-mail: melissa.intindola@wmich.edu

Sean E. Rogers, Ph.D.

School of Hotel Administration

Cornell University

565C Statler Hall

Ithaca, NY 14853

Tel. 386.453.3887 *

E-mail: ser265@cornell.edu

Carol Flinchbaugh, Ph.D.

Department of Management

New Mexico State University

BC Room 220

Las Cruces, NM 88003-8001

Tel. 575.646-5764

* E-mail: cflinch@nmsu.edu

Doug Della Pietra

Patient Experience \& Volunteers

Rochester General Hospital

1425 Portland Ave.

Rochester, NY 14621

E-mail: douglas.dellapietra@rochestergeneral.org 


\begin{abstract}
Purpose - The purpose of this paper is to explore the links between various characteristics of hospital administration and the utilization of classes of volunteer resource management (VRM) practices.
\end{abstract}

Design/methodology/approach - This paper uses original data collected via surveys of volunteer directors in 122 hospitals in five Northeastern and Southern US states.

Findings - Structural equation modeling results suggest that number of paid volunteer management staff, scope of responsibility of the primary volunteer administrator, and hospital size are positively associated with increased usage of certain VRM practices.

Research limitations/implications - First, the authors begin the exploration of VRM antecedents, and encourage others to continue this line of inquiry; and second, the authors assess dimensionality of practices, allowing future researchers to consider whether specific dimensions have a differential impact on key individual and organizational outcomes.

Practical implications - Based on the findings of a relationship between administrative characteristics and the on-the-ground execution of VRM practice, a baseline audit comparing current practices to those VRM practices presented here might be useful in determining what next steps may be taken to focus investments in VRM that can ultimately drive practice utilization.

Originality/value - The exploration of the dimensionality of volunteer management adds a novel perspective to both the academic study, and practice, of volunteer management. To the authors' knowledge, this is the first empirical categorization of VRM practices.

KEYWORDS: $\quad$ hospitals, human resources management, USA, VRM practices, volunteer director 


\section{Hospital Administrative Characteristics and Volunteer Resource Management Practices}

In 2013, the United States saw a continued decline in hospital and healthcare volunteerism for the first time in ten years (Bureau of Labor Statistics, 2014). When asked about the biggest concerns in healthcare volunteer management, volunteer administrators representing 105 hospitals and healthcare systems in the United States reported recruitment and retention in the face of declining volunteerism as a top priority (Rogers, Rogers, \& Boyd, 2013). Essentially, due to economic concerns and healthcare regulation, the need for volunteers in the healthcare sector is greater than ever and comes at a time when volunteerism has declined (Vinton, 2012). This suggests the need to consider the efficacy of current approaches to managing healthcare volunteers, and to examine whether there is room to improve the effectiveness of hospital volunteerism and management. This paper aims to investigate one such avenue -- volunteer human resource management (VRM) practices -- by focusing on the hospital administrative characteristics related to VRM.

Defined as "the adoption and effectiveness of HRM [human resource management] for voluntary human capital” (Cuskelly, Taylor, Hoye, \& Darcy, 2006:142), VRM considers the bundle of practices (e.g., written position descriptions for volunteers, formal volunteer orientation) that successfully promote the continued use of volunteer labor in an organization. While the practices themselves and their outcomes have received attention in the literature (Hager \& Brudney, 2004), the antecedents of VRM practices remain ambiguous. For example, Rogelberg and his colleagues (2010) observed that future volunteerism research "would benefit from a deeper and more nuanced examination of volunteer resource management practices” (p. 436), and they specifically call for examining the number and details of various practices rather than mere existence, as well as a focus on “classes of antecedents” such as the role volunteer 
coordinators and directors play in the effective use of volunteer labor. Along these lines, previous authors have used conceptual typologies to categorize volunteer management practice (e.g., Kyrwood \& Meneghetti, 2010), but to our knowledge none have empirically assessed whether or not VRM practices are utilized. This paper addresses such considerations, and extends the work of Hotchkiss, Fottler, and Unruh (2009) who demonstrated the benefits of volunteers for hospitals

We explore the role that five potential organizational administrative antecedents - (1) the size of the paid volunteer management staff, (2) the primary volunteer administrator's scope of responsibility, (3) whether or not volunteer management is housed in a hospital's foundation, (4) hospital size, and (5) whether or not volunteers are used to provide direct service to patients play in the managerial utilization of VRM practices in U.S. hospitals. In a recently published volunteer management paper, Hager \& Brudney (2011) suggested that volunteer management can be the result of "nature” or "nurture.” Nature refers to relatively stable organizational characteristics that cannot be easily overcome by managerial actions, while nurture refers to organizational conditions that can be influenced by leaders. Consistent with a "nurture" approach, the administrative antecedents we chose to examine are all conditions that can be influenced by either a hospital's top management team or the volunteer director. Thus, if any are positively related to an increased utilization of operationally-enhancing VRM practices, this knowledge can help to guide decisions about a hospital's administrative structure.

Additionally, we chose to focus on what we perceived to be organizational and administrative characteristics, rather than volunteer-focused variables. In this way variables like the presence of a dedicated volunteer administrator are important, but annual volunteer hours and a hospital's volunteer/staff ratio are not. Our fifth characteristics - whether volunteers provide 
direct patient services - might seem like an exception to our logic; however, we see this as an issue of job design and thus more an organizational characteristic than a volunteer-driven one.

This study attempts to make four key contributions to the science and practice of healthcare volunteer management. First, it explores possible antecedents of hospital VRM practice utilization, something that has heretofore been largely overlooked in the healthcare and volunteerism literatures. Second, by analyzing the antecedents of 23 VRM practices pulled from various “best practices” listings (Brudney, 1999; Ellis, 2010; Hager \& Brudney, 2004; Kyrwood \& Meneghetti, 2010; Rogelberg et al., 2010; The UPS Foundation, 2002), it provides a comprehensively broad and wide-sweeping look into volunteer management that can provide practical guidance for healthcare VRM professionals. Expanding the listing of potential VRM practices when doing empirical volunteer management work is theoretically relevant, as Rogelberg and colleagues' (2010) results suggested that VRM practices have a cumulative effect, with an increase in practices being associated with improved volunteer experiences.

Relatedly, third, we examine whether these VRM practices pulled from prior texts tend to be utilized as "groups” of practices. The study of hospital volunteer management has tended to look at VRM practices as individual practices; however, as Rogelberg and his colleagues (2010) note, VRM practices may have some cumulative effects on outcomes. Thus, as explained in detail later, we factor-analyze the individual practices to assess how certain practices fit together, and to determine whether any theoretical or practical "dimensions” of VRM practices emerge.

Fourth, the continuous measurement approach of VRM practices taken in this study allows for a more fine-grained analysis of VRM utilization, as well as a clear differentiation between practice adoption and practice utilization. Whereas many studies of VRM practices query respondents on whether or not specific practices exist (for example, Rogelberg et al., 
2010), in this study respondents were specifically asked how frequently each of the 23 VRM practices was used within their organization. As with expanding the number of VRM practices described above, making the distinction between adoption of VRM, and actual implementation and frequency of VRM, has key theoretical implications. Numerous studies in the performance management literature clearly demonstrate a consistent gap between the adoption and utilization of managerial initiatives, with each having distinct individual- and organizational-level antecedents and consequences (for example, de Lancer Julnes \& Holzer, 2001).

The remainder of the paper is structured as follows. We first identify five potential administrative characteristics of the volunteer management function within hospitals, and describe their potential impact on the utilization of such groups of VRM practices as job design, staffing, orientation, and performance management using several theoretical perspectives. Next, a discussion of the data and methods used to explore these relationships is presented, as are the results of data analysis. In the final section the findings are discussed, and managerial implications, study limitations, and directions for future research are considered.

\section{Theoretical Development and Research Questions}

Hager and Brudney (2004) arguably provide the most focused analysis of VRM practices. Using a nationally-representative sample of 2,993 charities that filed IRS Form 990s in 2000, they explored the extent to which organizations adopted nine volunteer management practices. Specifically, they asked respondents whether their charity had adopted each of the nine practices, and then tested the impact of adoption on volunteer retention. Their analysis concluded that some VRM practices, but not all, have a positive effect on retention.

While their analysis also included measures of organizational characteristics (for example, organization size) and organizational investment in the volunteer workforce (for 
example, funding levels to support volunteers, or board member attitudes toward volunteers), notably absent were the administrative “classes of antecedents” hinted about by Rogelberg and his colleagues. These include detailed characteristics of the organization's volunteer administration function. Since Hager and Brudney (2004) and others have positively linked macro organizational characteristics such as size and age to volunteer managerial practices (and indeed, organization age and size have been related to managerial formalism and organizational bureaucracy in the larger literature on organizations, work, and paid employees), exploring the potential role of administrative characteristics might help to provide an explanatory bridge between macro organizational aspects and volunteer management. ${ }^{i}$ Thus, in addition to size of an organization, we focus on volunteer administrative characteristics that may reflect operational decisions toward volunteer management. Each of the five antecedents we examine in this paper is discussed below.

\section{Size of the Paid Volunteer Management Staff}

The size of the paid staff charged with managing volunteers may affect the organization's likeliness to adopt and utilize VRM practices. In particular, organizations that pay more than one person to manage volunteers may do so because they are more cognizant of the potential return on investment provided by volunteers. Handy and Srinivasan (2004) valued volunteers at \$6.84 returned for every dollar spent on their management - a return of $684 \%$ - and suggest that these results justify resource allocation decisions surrounding the funding of a well-run volunteer program. The creation and maintenance of a well-run volunteer program may therefore be considered an investment by some hospitals, which in turn prompts greater use of volunteer management. 


\section{Volunteer Administrator's Scope of Responsibility}

Given the under-creation of formal volunteer management programs in many organizations, we begin by drawing from the broad literature on job redesign to explain the potential consequences of altering employee tasks for the purpose of reducing monotony, and/or more fully utilizing the potential skills and capabilities of the individual, and/or allowing the worker more freedom and responsibility in the performance of his job” (Reif \& Schoderbek, 1966/l 17), the primary negative consequences of redesign stems from a perceived loss of security. That is, if employees feel that their jobs are redesigned to include tasks/roles with which they were unfamiliar, they are more likely to respond negatively. This is consistent with Born and Molleman's (1996) finding 30 years later that workers need to feel 'in control' of their added responsibilities. Most recently, these concerns are specifically recognized within our context by Layman (2007), who recommends very careful consideration be giving to redesigning any job within a hospital setting.

In addition to job design issues, research on role ambiguity and role conflict explains how a perceived loss of control over work roles can affect the individual. Miles (1976) demonstrated that role ambiguity is related to four job-related outcomes: tension/ anxiety, job satisfaction, attitudes toward role senders, and perceived performance effectiveness. Unpredictable results and uncertain behavioral requirements are more detrimental than incongruence or incompatibility between role requirements (Rizzo, House, \& Lirtzman, 1970). This suggests that the increased ambiguity associated with expansion of scope is important. Therefore, assigning a hospital employee the role of volunteer administrator as an additional role can have a potentially devastating effect on VRM. 
Taken together, healthcare staff members who have been assigned the task of managing volunteers, and who see this as outside of their primary scope of responsibility or as an added task or burden, may be less likely to devote already-limited resources toward the enactment of volunteer workforce-enhancing HR practices. Such a position could limit the effectiveness of volunteer activities, and prevent their full positive impact on patient satisfaction and hospital operations.

\section{Location of the VRM Function}

Our examination into the importance of this administrative characteristic is largely exploratory. To our knowledge, there are no prior studies which identify certain volunteer management hierarchical structures and reporting relationships as superior to others; thus, our ability to theorize here is limited. However, we posit that the placement of VRM within the organization's hierarchy may economically signal its perceived strategic importance, relative to other hospital functions, and that this may affect VRM utilization.

In particular, hospital foundations housing volunteers may indicate an increased willingness to focus on volunteer management. Hospital foundations are typically non-profit entities affiliated with hospitals and tasked with a variety of functions ranging from generally increasing public awareness of the hospital's mission to specifically procuring donations of time and money. This may include the provision and maintenance of a volunteer program. This may be because senior hospital leadership may connect volunteerism to the same motivation that leads individuals to donate money. Therefore, for many executives it seems logical to link volunteer management with the work of hospital foundations and the connection with the given community - be it donations of time or money. For example, one Western Michigan hospital runs a separate, non-profit foundation through which community members can sign up to be 
hospital volunteers in addition to donating to the hospital. Similar examples abound (e.g., St. Jude’s ‘Ways to Help’ website: http://www.stjude.org/waystohelp). Further, McGregor-Lowndes and Flack (2002) deemed volunteers the ‘competitive advantage’ of hospital foundations. Therefore, foundations may be 'laser-focused' on the management of volunteers in order to continue to maintain their role in the foundation's ability to fundraise and, in turn, the hospital's provision of services and subsequent competitive positioning.

\section{Hospital Size}

Several prior studies find a link between organization size and the formalization of volunteer management (c.f., Gaskin \& Davis Smith, 1995; Ambrose \& Paine, 2006; Hager \& Brudney, 2004; Lynch \& Smith, 2009). We acknowledge this relationship, but specifically include size as a variable to be tested, particularly in the added presence of the other previouslyunexamined administrative characteristics. Size here is determined by number of paid employees working at the hospital, data publicly available on the American Hospital Association’s Healthcare Data Viewer website.

\section{Whether or not Volunteers Provide Direct Patient Service}

Hager and Brudney (2004) note that: "The work that volunteers do also influences adoption of management practices” (pg. 7). Their 2004 study of nearly 3,000 charities provides evidence that charities that primarily use volunteers to perform direct service tasks (such as mentoring or tutoring in their study) tend to adopt more volunteer management practices than organizations that primarily rely upon volunteers to perform non-client-contact tasks. We build upon their findings to examine whether this relationship also applies to the increased utilization of volunteer management practices, and whether it holds in the presence of the other administrative characteristics. 
Considering the preceding discussion about potential administrative antecedents to VRM utilization, in this paper we investigate the following research questions (RQs):

RQ1: What effect does the size of the paid volunteer management staff have on the utilization of VRM practices?

RQ2: What effect does the primary volunteer administrator's scope of responsibility (whether they are solely responsible for volunteer management, or have other administrative responsibilities in addition to VRM) have on the usage of VRM practices? RQ3: What effect does the volunteer administration function's location within the organizational structure - particularly whether or not it is housed within a hospital's foundation - have on the utilization of VRM practices?

RQ4: Does organization size continue to be positively related to the use of volunteer management practices in the presence of the administrative characteristics of size of the paid volunteer management staff, the volunteer manager's scope of responsibilities, and the volunteer management function's location within organizational hierarchy? RQ5: Does having volunteers work primarily in direct service roles continue to be positively related to the use of volunteer management practices in the presence of the administrative characteristics of size of the paid volunteer management staff, the volunteer manager's scope of responsibilities, and the volunteer management function's location within organizational hierarchy?

\section{Methods}

\section{Participants}

In August 2011, paper-and-pencil surveys with postage-paid return envelopes were mailed to the "Director of Volunteer Services" at 496 hospitals in five states in the Northeast and 
Southern U.S. These 496 hospitals represented a complete listing of hospitals in those five states on the Medicare Hospital Compare website (www.hospitalcompare.hhs.gov). In October 2011, follow-up reminders were mailed. By December 31, 2011, the end of the survey collection period, 131 completed surveys had been returned, for a response rate of 26 percent. Despite our best efforts, respondents were primarily from those hospitals residing in the Northeast, a consideration we note in greater detail in the limitations section. Demographic data such as hospital size were obtained from publicly-available sources; this will be explained in more detail below. Given small amounts of missing data in the variables tested for this paper, the final $N$ for our analysis is 122 .

\section{Measures}

The authors collected the study variables via survey with the exception of hospital size, which was taken from the American Hospital Association's Healthcare Data Viewer website. All scales used the following five-point Likert-type scale unless otherwise noted: $(1=$ "never,” 2 = “not very frequently,” 3 = “sometimes,” 4 = “very frequently,” 5 = “always”).

Size of paid volunteer management staff. Respondents were asked to indicate their hospital's size of the paid volunteer staff in full-time equivalents, specifically excluding any volunteers or other unpaid personnel who act in a supervisory or managerial role to other volunteers. This is analyzed as a continuous variable using the number provided by respondents.

Volunteer administrator's scope of responsibility. Scope of responsibility is a dichotomous variable that assesses the primary volunteer administrator's scope of responsibility to only the management of volunteers and volunteer functions, versus responsibility for additional duties beyond volunteer coordination. Categorization for this variable was determined manually via a content analysis of the primary volunteer administrator's self-reported job title. If 
their title contained only volunteer responsibilities, such as director of volunteer services, volunteer coordinator, volunteer services manager they were coded as " 1 .” Otherwise, they were coded “0.”

Location of VRM function. Foundation reporting describes whether or not the volunteer administration function is housed in a hospital's foundation. This is measured as a dichotomous variable. Respondents were asked to manually write in what hospital department volunteer management reported to. Foundations were coded as “1” and all other departments were coded as “0.”

Hospital size. This variable represents the natural log of the number of paid employees working at a given hospital, and was obtained from "Quick Reports” pulled from the American Hospital Association’s Healthcare Data Viewer website (www.ahadataviewer.com).

Whether or not Volunteers Provide Direct Patient Service. Direct patient service is a dichotomous variable that measures whether or not volunteers provide direct patient service. Responding volunteer directors were asked whether their volunteer workforce was primarily responsible for providing direct service to patients, or other forms of indirect service (to include internal and/or external administrative duties).

Volunteer Resource Management Practices (VRM). VRM practices were measured by asking respondents to indicate how frequently each of the 23 VRM practices were used in their workplace. The use of a continuous scale allowed us to assess the level of VRM utilization at each hospital. As previously noted, the 23 VRM practices used in this paper are pulled from several “best practices” listings (Brudney, 1999; Ellis, 2010; Hager \& Brudney, 2004; Kyrwood \& Meneghetti, 2010; Rogelberg et al., 2010; The UPS Foundation, 2002). This was done to capture the widest possible array of volunteer management practices nonprofits may be utilizing. 
Examples include: “Our organization maintains a written statement or philosophy regarding volunteer involvement," "We have written position descriptions for volunteer roles," We have a formal, structured orientation for new volunteers,” and “Our top volunteer administrator is involved in organizational planning and strategy activities at the highest levels of management.” A full list of the practices are provided in Table 1.

Insert Table 1 about here

\section{Results}

\section{Assessing the Dimensionality of Volunteer Management Practices}

Prior to examining the antecedents to VRM utilization, we wanted to see if commonlyused VRM practices fit together in their utilization by volunteer directors. We conducted confirmatory factor analysis (CFA) on responses from volunteer directors at 122 hospitals using Mplus (Version 7.11). Incorporating an inductive approach as outlined earlier, an initial 5-factor structure of the 23 individual VRM practices emerged, including the broad volunteer management practices categories of (1) job design, (2) staffing, (3) orientation, training, and development, (4) performance management and supervision, and (5) communication, recognition, and rewards. However, this 5-factor structure provided poor model fit $\left(\chi^{2}(220)=\right.$ 329.24, RMSEA = $0.06(90 \%$ C.I. = 0.05 0.08), CFI = 0.84, TLI = 0.82). Of particular concern, the "communication, recognition, and rewards" dimension maintained correlations of greater than one with the other four dimensions, suggesting that it was measuring ideas similar in nature to those contained in the other factors. To correct the error of shared meaning across these different constructs, we pruned the three poor-fitting items associated with this dimension. In 
addition, we pruned one item associated with the job design dimension and were left with 19 VRM practices across four VRM practice dimensions: (1) job design, (2) staffing, (3) orientation, training, and development, and (4) performance management. In Table 1, the final listing of each of the 19 VRM practices examined is provided under its associated dimension.

The best-fitting factor structure that maintained the largest number of indicators reported good model fit: $\left(\chi^{2}(140)=169.56\right.$, RMSEA $=0.04(90 \%$ C.I. $=0.010 .06)$, CFI $=0.95$, TLI $=$ 0.94). All factor loadings maintained significance and demonstrated commonly accepted loading levels for examining exploratory relationships, such as the grouping of VRM practices (Thompson, 2004).

To verify that the four dimension factor structure is the best fitting model, we also compared the four-factor model with a single-factor model. The four-factor model provides a more acceptable fit in comparison to a single factor $\left(\chi^{2}(\mathrm{df}=150)=198.22, \mathrm{RMSEA}=0.05[90 \%\right.$ C.I. $=0.03$ 0.07], CFI $=0.92, \mathrm{TLI}=0.91)$.

Thus, the final four-factor structure not only demonstrates good model fit, but also honors the inductive and deductive item generation processes described earlier. Moreover, this suggests that the VRM practices used in our sample appear to represent dimensions, such as job design, staffing, orientation, and performance management. In the next section, we will examine whether organizational administrative characteristics help to explain which groups of VRM practices tend to be utilized by the hospitals in our sample.

Statistical Analyses of the Organizational Antecedents to VRM Utilization

Next, we examined the proposed relationships between administrative characteristics and volunteer management. Means, standardized deviations and pairwise correlations are reported in Table 2. 
In order to investigate the relationships between the predictor variables and VRM, the authors employed structural equation modeling (SEM) techniques. SEM has several advantages over traditional multivariate regression techniques (e.g. OLS) including the correction of measurement errors and improving statistical power through the use of full-information maximum likelihood (FIML) estimation. FIML has an advantage over listwise or pairwise deletion because it results in unbiased parameter estimates (Wothke, 2000). Prior to examining the study hypotheses, tests of normality were conducted and no violations existed.

\section{Measurement Model}

Following convention, we first assessed the fit of our data to a measurement model.

Model 1 depicts the proposed measurement model (see Table 3). This model included ten factors (four VRM dimensions, size of the paid volunteer management staff, the volunteer administrator's scope of responsibility, location of the VRM function, hospital size, and volunteer involvement in direct and indirect services; this last variable constitutes two separate variables, one for direct service, and another for indirect service). The proposed model for the hypothesized regression relationships maintained acceptable fit $\left(\chi^{2}(228)=267.09\right.$, RMSEA $=$ 0.04 [90\% C.I. $=0.01$ 0.06], CFI $=0.94, \mathrm{TLI}=0.92$ ). Next, in Model 2, 3, and 4 we tested the construct validity among the volunteer administrator variables: size of paid volunteer management staff, volunteer administrator's scope of responsibility, and location of the VRM function. Finally, in Model 5, we loaded all items onto one factor to examine the potential impact of common method bias. This model demonstrated worse model fit than our baseline model 
$(\Delta \chi 2(93.05)=360.14, \mathrm{p}<0.01)$, indicating that common method bias was not driving our factor structure. As shown in Table 3, the hypothesized model provided better model fit than any of the other plausible alternatives.

Insert Table 3 about here

Tests of Propositions in Research Questions 1-5

Given the supportive findings for the proposed measurement model, we next examined the study's research questions. The first three research questions examined the administrative nature of the hospitals’ volunteer management function and the last two assessed hospital organizational characteristics. These research questions were examined simultaneously by testing direct relationships across the five antecedent variables and the four-factor construct of volunteer management. See Figure 1 for results.

Insert Figure 1 about here

Research question 1 examined the relationship between size of the paid volunteer management staff and utilization of VRM practices. We found strong support for the value of this relationship across three of the four VRM dimensions. The number of paid volunteer management staff members had a significant positive relationship with utilization of job design (0.27, $\mathrm{p}<.05)$; orientation, training, and development $(0.25, \mathrm{p}<.05)$; and performance management and supervision $(0.23, \mathrm{p}<.05)$. Paid volunteer management staff was not statistically significantly related to the utilization of staffing VRM practices. 
Next, we assessed the importance of the primary volunteer administrator's scope of responsibility on the utilization of our four groups of VRM practices. This antecedent had a significant positive relationship with size of the paid volunteer management staff. This finding suggests that when volunteer directors had primary responsibility for managing volunteers - as opposed to volunteers in addition to other duties - they tended to utilize greater staffing-related VRM practices $(0.25, \mathrm{p}<.05)$. No significant pathways were found between scope of responsibility and the other three VRM categories of job design, training and development, or performance management.

We then tested the effects of the volunteer administration function's location within the hospital foundation on the utilization of VRM practices. We found that administrators' reporting relationship to a foundation had no significant relationship with the VRM usage across any of the four dimensions. Given the non-significance of the hospital foundation on VRM usage, we conducted post hoc tests examining alternative reporting locations of the volunteer administrator, including the human resources department, marketing department, executive administration, or other locations. The follow-up analyses also reported non-significant relationships between the utilization of VRM practices and the other reporting locations of volunteer administrator function. This suggests that the reporting location of the volunteer administrator has no effect on the utilization of VRM practices.

The final two hypotheses examined the relationship between hospital characteristics and the usage of VRM practices. Hypothesis 4 tested the differences in HRM usage across hospital size. As expected, differences in hospital size led to significant positive relationships in the job design (0.263, $\mathrm{p}<.05)$ and staffing $(0.340, \mathrm{p}<.01)$ dimensions, such that larger hospitals appear more intentional in developing policies and practices related to volunteer recruitment and daily 
role expectations. Last, we also examined whether there are different VRM practices depending on the type of volunteer responsibilities. More specifically, Hypothesis 5 examined the differences in volunteer practices between direct and indirect volunteer services. We found that the use of volunteers in direct service to patients led to a positive relationship with staffing practices $(0.228, \mathrm{p}<.05)$. Positive, but non-significant relationships were reported between use of volunteers in direct service roles and the other three VRM dimensions. Interestingly, the presence of volunteers in indirect services led to a significant negative pathway with the performance management and supervision volunteer management dimension $(-0.178, \mathrm{p}<.10)$. Thus, our findings find significant relationships between hospital characteristics and the use of VRM practices, supporting both Hypothesis 4 and Hypothesis 5.

\section{Discussion and Conclusion}

These results provide a first look into the role administrative aspects of the volunteer management function play in the utilization of VRM practices in hospitals, and also test prior findings about organizational characteristics (namely, size and volunteer task type) in the presence of these administrative antecedents. In our study, hospitals that devoted more organizational resources toward the management of volunteers - in the form of having more paid volunteer management professionals, and empowering volunteer directors to focus primarily on VRM - tended to utilize more VRM practices. This is noteworthy since such practices have been shown to result in positive individual and organizational outcomes, including retention (Hager \& Brudney, 2004) and harmonious volunteer-paid staff relations (Rogelberg et al., 2010). Also, and in line with prior research (e.g., Hager \& Brudney, 2004), organization size and the type of tasks volunteers engage in have an effect on volunteer management. Larger hospitals tended to use VRM practices to a greater extent. 
In light of clear standards set forth by regulatory bodies such as The Joint Commission, the finding that only one of the four VRM dimensions was positively related to hospitals using volunteers primarily for direct service is somewhat surprising. According to its website, the Joint Commission "accredits and certifies more than 20,500 health care organizations and programs in the United States. Joint Commission accreditation and certification is recognized nationwide as a symbol of quality that reflects an organization's commitment to meeting certain performance standards.” Related to volunteerism, the Joint Commission declares: "When volunteers perform patient care or services the organizations must manage volunteer personnel just as they must manage services and personnel who are provided by direct employees.” Therefore, one could expect wider utilization of the other VRM dimensions, especially the orientation-related and performance VRM practices. Future research should more closely examine the nature of volunteer work roles and assignments in U.S. hospitals.

Service organizations and charities of all sorts grapple with issues of resource constraints and the allocation of responsibility to its paid employees. Particularly as it relates to volunteer management in healthcare organizations, hospitals have a choice to make about how they will manage their volunteer workforces. Do they hire one person or multiple individuals to manage volunteers? Should their "volunteer person” be dedicated to managing the volunteer function, or should managing volunteers be an add-on responsibility that is tacked onto an already-existing position? Our data suggest that more active volunteer management, in the form of utilization of best practices, occurs when organizational investments are used to treat the management of volunteers as a separate, stand-alone function. Additionally, research shows that more active volunteer management leads to increased volunteer job-related competencies and opportunities to perform at higher levels, which results in enhanced organizational performance. Volunteer 
directors who must manage volunteers in addition to other hospital functions like customer service or public relations may simply not have enough time or capacity to focus on focused volunteer management practices such as creating detailed policies concerning employeevolunteer relations, or conducting strategic recruitment efforts to match volunteers with specific skills to key roles.

Based on our findings of a relationship between administrative characteristics and the onthe-ground execution of VRM practice, we offer specific practical recommendations for healthcare volunteer administration professionals and organizations. Perhaps a first step is for volunteer directors to engage their direct leader, and the organization's leadership more broadly, in philosophical conversations about the place and role volunteers have in the organization and its strategic initiatives. Similarly, a baseline audit comparing current practices to those outlined in Table 1 might be useful in determining what next steps may be taken to focus investments in VRM that can ultimately drive practice utilization. Given the ubiquitous and long-standing tradition of hospital volunteers, it is in the best interest of all stakeholders - including volunteers, volunteer administrators, hospital patients, paid employees, hospital leadership, and the local community - for a hospital's volunteer workforce to be positioned to provide the greatest value in their work.

In addition to providing hospital- and healthcare-specific insights, this study more generally adds to the body of empirical knowledge concerning VRM by responding to calls by Rogelberg and his colleagues (2010) and others to direct attention to a wide range of antecedents of VRM practices. We have done this partly, and encourage others to continue this line of inquiry. Particular suggestions for future research include assessing the impact of executive and other hospital personnel support for, and attitudes towards, volunteers, as well as exploration into 
whether and how the different categories of VRM practices impact volunteer outcomes. Additionally, future research should collect data on volunteer demographics in an effort to explore how the volunteers' and organizations' characteristics interact, as in the case of whether a hospital assigns volunteers to a direct service provision role or not.

Our exploration of the dimensionality of volunteer management adds a novel perspective to both the academic study, and practice, of volunteer management. The volunteer directors in our sample did not appear to use these practices in isolation. Rather, their utilization seemed to "move” with other practices to form specific conceptualizations of the various aspects of VRM job design; staffing; orientation, training, and development; and performance management and supervision. To our knowledge, this is the first empirical categorization of VRM practices. From an antecedent perspective, these dimensions allow us to hone in on what administrative characteristics matter - or don't matter as in the case of the reporting location for the volunteer administrator - for VRM utilization in specific areas. One possible avenue for future research is to explore whether these dimensions have a differential impact on key individual and organizational outcomes. What matters more for volunteer turnover - having a clear idea of the volunteer job to be performed (the job design dimension), or receiving timely feedback on one’s job performance (the performance management and supervision dimension)? What has a greater impact on patient satisfaction - accurately pairing volunteer skills and job requirements (the staffing dimension), or providing volunteers with continuous training on patient safety techniques (the training and development dimension)? Further research should also continue to explore the location of the volunteer management function. Despite our inability to find significance for differing locations, it remains an important structural question for hospitals. 
Lastly, one may posit that our most interesting and important finding is that which goes beyond staffing. It seems logical that volunteers take up more time on the front end (that is, in staffing). However, long-term volunteers may receive less attention, particularly in underdeveloped and/or undermanaged volunteer programs. Thus, our findings linking a dedicated paid volunteer management staff person to job design, orientation and performance suggests that while anyone may be able to orient the volunteer to the hospital, more dedicated resources in the form of a paid volunteer management staff person could have a number of interesting volunteer outcomes, perhaps including the provision of better-quality volunteer service. Future research should further explore these significant links.

Our findings are not without some limitations. Of primary concern is the limited geographical dispersion of our respondents - the sample was comprised of only hospitals in five U.S. states, mostly clustered in the Northeast. Although our non-response bias test indicates no significant differences between the demographic characteristics of the hospitals who responded to our survey and those who were invited to participate but did not, subsequent research studies can add representative value by expanding to larger national, and even global, populations of hospitals. This would have the added benefit of enlarging the number of responses, thereby strengthening the robustness of any statistical results. Another limitation is the method we used to assess the scope of VRM responsibility. We assessed scope by analyzing the job titles of volunteer administrators. As Paul Osterman (2008) notes in his writings about the flattening of contemporary work organizations, workers are increasingly taking on more and varied responsibilities, oftentimes without corresponding enlargements in position or pay. As such, while our follow-up conversations with several of the respondents gave us an anecdotal measure of confidence in the accuracy of our classifications, there remains a small chance that our 
approach and follow-up may not have provided us with a complete picture. A more precise method would have been to ask respondents directly about the scope of their duties; however, such a question was not included in the questionnaires distributed to the sample. We suggest such an approach for future research.

Despite these limitations, we believe that our findings help to fill in our theoretical understanding about the underpinnings of high-performance volunteer management. They also help to provide practitioners, particularly healthcare organization leaders and executives, with compelling evidence for investing organizational resources into volunteer management. Oftentimes, advocates for volunteers anecdotally lament about how volunteers are undervalued and underappreciated. This paper adds to the ever-increasing case that organizational investments in the volunteer function might very well lead to a virtuous cycle of enhanced volunteer and organizational outcomes. Our findings further encourage exploration of linkages between organizational investments in volunteer administration, and volunteer and organizational outcomes. Hospitals and other organizations that rely on volunteer labor would do well by viewing their volunteer workforces as equal partners in the quest for organizational success, and by developing administrative and management structures that allow volunteers to fully contribute to organizational objectives. 


\section{References}

Ambrose, T. \& Paine, C. (2006) Museum Basics, Routledge, London

Beehr, T. A., \& Gupta, N. (1978). A note on the structure of employee withdrawal. Organizational behavior and human performance, 21(1), 73-79.

Born, L., \& Molleman, E. (1996). Empowerment and rewards: a case study. Empowerment in Organizations, 4(3), 30-33.

Brudney, J. L. (1999). The effective use of volunteers: Best practices for the public sector. Law and Contemporary Problems, 62: 219-255.

Brudney, J. L., \& Meijs, L. C. (2009). It Ain't Natural toward a new (natural) resource conceptualization for volunteer management. Nonprofit and Voluntary Sector Quarterly, 38(4), $564-581$.

Conway, J. M. (1999). Distinguishing contextual performance from task performance for managerial jobs. Journal of Applied Psychology, 84: 3-13.

Corporation for National and Community Service. Volunteering in America 2011: Research highlights. Accessed October 30, 2011. http://www.volunteeringinamerica.gov/assets/resources/FactSheetFinal.pdf

Cuskelly, G., Taylor, T., Hoye, R., \& Darcy, S. (2006). Volunteer management practices and volunteer retention: A human resource management approach. Sport Management Review, 9(2), 141-163.

de Lancer Julnes, P., \& Holzer, M. (2001). Promoting the utilization of performance measures in public organizations: An empirical study of the factors affecting adoption and implementation. Public Administration Review, 61: 693-708. 
Delaney, J. T., \& Huselid, M. A. (1996). The impact of human resource management practices on perceptions of organizational performance. Academy of Management Journal, 39(4), 949-969.

Ellis, S. J. (2010). From the top down: The executive role in successful volunteer involvement. Philadelphia: Energize, Inc.

Freeman, R. B. (1997). Working for nothing: The supply of volunteer labor. Journal of Labor Economics, 15: S140-S166.

Gaskin, K. \& Davis Smith, J. (1995) A New Civic Europe? A study of the extent and role of volunteering, The Volunteer Centre UK, Berkhamstead.

Grinyer, P. H., \& Yasai-Ardekani, M. (1981). Strategy, structure, size and bureaucracy. Academy of Management journal, 24(3), 471-486.

Hager, M. A., \& Brudney, J. L. (2004). Volunteer management practices and retention of volunteers. Washington, D. C.: The Urban Institute.

Hager, M. A., \& Brudney, J. L. (2011). Problems recruiting volunteers: Nature versus nurture. Nonprofit Management and Leadership, 22(2), 137-157.

Handy, F., \& Srinivasan, N. (2004). Valuing volunteers: An economic evaluation of the net benefits of hospital volunteers. Nonprofit and Voluntary Sector Quarterly, 33(1), 28-54.

Hotchkiss, R. B., Fottler, M. D., \& Unruh, L. (2008, August). Valuing volunteers: the impact of volunteerism on hospital performance. In Academy of Management Proceedings (Vol. 2008, No. 1, pp. 1-6). Academy of Management.

Hotchkiss, R. B., Fottler, M. D., \& Unruh, L. (2009). Valuing volunteers: The impact of volunteerism on hospital performance" Health Care Management Review, 34(2), 119128. 
Kong, E. (2008). The development of strategic management in the non-profit context: Intellectual capital in social service non-profit organizations. International Journal of Management Reviews, 10(3), 281-299.

Kyrwood, D. L., \& Meneghetti, M. M. (2010). Volunteer staffing and development.” In K. Seel (Ed.), Volunteer administration: Professional practice, 143-214. Ontario, Canada: Council for Certification in Volunteer Administration.

Layman, E. J. (2007). Job redesign and the health care manager. The Health Care Manager, 26(2), 98-110.

Lee, K., \& Allen, N. J. (2002). Organizational citizenship behavior and workplace deviance: The role of affect and cognitions. Journal of Applied Psychology, 87: 131-142.

Lepak, D. P., \& Snell, S. A. (2002). Examining the human resource architecture: The relationships among human capital, employment, and human resource configurations. Journal of Management, 28(4), 517-543.

Lynch, S., \& Smith, K. (2009). The dilemma of judging unpaid workers. Personnel Review, 39(1), 80-95.

McGregor-Lowndes, M., \& Flack, T. (2002). The border between government and charity: a case study of Queensland Hospital Foundations. Third Sector Review, 8(1), 99-115.

Miles, R. H. (1976). A comparison of the relative impacts of role perceptions of ambiguity and conflict by role. Academy of Management Journal, 19(1), 25-35.

Millette, V., \& Gagne, M. (2008). Designing volunteers’ tasks to maximize motivation, satisfaction and performance: The impact of job characteristics on volunteer engagement. Motivation and Emotion, 32: 11-22. 
Newman, W. H., \& Wallender, H. W. (1978). Managing Not-for-Prof it Enterprises. Academy of Management Review, 3(1), 24-31.

Osterman, P. (2008). The truth about middle managers: Who they are, how they work, why they matter. Harvard Business Press.

Reif, W. E., \& Schoderbek, P. P. (1966). Job enlargement: Antidote to apathy. Human Resource Management, 5(1), 16-23.

Rizzo, J. R., House, R. J., \& Lirtzman, S. I. (1970). Role conflict and ambiguity in complex organizations. Administrative Science Quarterly, 150-163.

Rogelberg, S. G., Allen, J.A., Conway, J. M., Goh, A., Currie, L., \& McFarland, B. (2010). Employee experience with volunteers: Assessment, description, antecedents, and outcomes. Nonprofit Management \& Leadership, 20: 423-444.

Rogers, S. E., Rogers, C. M., \& Boyd, K. D. (2013). Challenges and Opportunities in Healthcare Volunteer Management: Insights from Volunteer Administrators. Hospital topics, 91(2), 43-51.

St. Jude’s 'Ways to Help’: http://www.stjude.org/waystohelp

The UPS Foundation. (2002). A guide to investing in volunteer resources management: Improve your philanthropic portfolio. Retrieved March 7, 2011 from http://www.energizeinc.com/art/documents/invest_vrm_guide.pdf.

Thompson, B. (2004), Exploratory and Confirmatory Factor Analysis: Understanding Concepts and Applications, American Psychological Association, Washington, DC

Vinton, L. (2012). Professional administration of volunteer programs now more than ever: A case example. Administration in Social Work, 36(2), 133-148. 
Williamson, O. (1971). The multi-divisional hypothesis. In R. Marris \& A. Wood (Eds.), The corporate economy. London: Macmiltan.

Wing, K. T., Pollak, T. H., \& Blackwood, A. (2008). The nonprofit almanac 2008. Washington, D.C.: The Urban Institute Press.

Wothke, W. 2000. Longitudinal and multigroup modeling with missing data. In T. D. Little, K. U. Schnabel, \& J. Baumert (Eds.), Modeling Longitudinal and Multilevel Data. Mahwah, NJ: Erlbaum.

Xie, J. L., \& Johns, G. (1995). Job scope and stress: Can job scope be too high? Academy of Management Journal, 38(5), 1288-1309. 
Table 1. Factor loadings for VRM dimensions

\begin{tabular}{|c|c|c|c|c|}
\hline Dimension & $\underline{\underline{\text { Item }}}$ & Loading & $\begin{array}{l}\underline{\underline{\text { Standard }}} \\
\text { Error }\end{array}$ & $\begin{array}{l}\text { Two- } \\
\text { tailed } \\
\text { p-value }\end{array}$ \\
\hline \multirow[t]{4}{*}{ Job Design } & $\begin{array}{l}\text { Our organization maintains a written statement } \\
\text { or philosophy regarding volunteer } \\
\text { involvement. }\end{array}$ & 0.546 & 0.079 & 0.00 \\
\hline & $\begin{array}{l}\text { We maintain written policies and procedures } \\
\text { for paid staff working with volunteers }\end{array}$ & 0.527 & 0.080 & 0.00 \\
\hline & $\begin{array}{l}\text { Our organization provides liability coverage or } \\
\text { insurance protection for volunteers }\end{array}$ & 0.346 & 0.093 & 0.00 \\
\hline & $\begin{array}{l}\text { We conduct periodic needs assessment to } \\
\text { determine how volunteers should be involved } \\
\text { to support the organization's mission }\end{array}$ & 0.535 & 0.079 & 0.00 \\
\hline \multirow[t]{3}{*}{ Staffing } & $\begin{array}{l}\text { We have written position descriptions for } \\
\text { volunteer roles }\end{array}$ & 0.591 & 0.075 & 0.00 \\
\hline & $\begin{array}{l}\text { We use multiple media outlets (Internet, direct } \\
\text { mail, volunteer recruiting fairs, etc.) to recruit } \\
\text { volunteers }\end{array}$ & 0.391 & 0.088 & 0.00 \\
\hline & $\begin{array}{l}\text { Volunteers are sought out based on having } \\
\text { skills that match position requirements }\end{array}$ & 0.577 & 0.073 & 0.00 \\
\hline
\end{tabular}


Administrative Characteristics and VRM

\begin{tabular}{|c|c|c|c|c|}
\hline & $\begin{array}{l}\text { We conduct a formal volunteer screening and } \\
\text { selection process (including position } \\
\text { applications, interviews, background checks, } \\
\text { reference checks, etc.) }\end{array}$ & 0.593 & 0.076 & 0.00 \\
\hline \multirow[t]{6}{*}{ Orientation } & $\begin{array}{l}\text { We have a formal, structured orientation for } \\
\text { new volunteers }\end{array}$ & 0.316 & 0.089 & 0.00 \\
\hline & $\begin{array}{l}\text { We offer regular ongoing training and } \\
\text { professional development opportunities for } \\
\text { volunteers }\end{array}$ & 0.528 & 0.073 & 0.00 \\
\hline & $\begin{array}{l}\text { We provide our paid staff training in working } \\
\text { with volunteers }\end{array}$ & 0.577 & 0.070 & 0.00 \\
\hline & $\begin{array}{l}\text { Paid staff new hires are told about why and } \\
\text { how volunteers are involved in our } \\
\text { organization }\end{array}$ & 0.543 & 0.074 & 0.00 \\
\hline & $\begin{array}{l}\text { The primary volunteer administrator receives } \\
\text { funding to join job-relevant professional } \\
\text { groups, attend conferences, or subscribe to } \\
\text { journals }\end{array}$ & 0.470 & 0.079 & 0.00 \\
\hline & $\begin{array}{l}\text { Volunteers are provided information about } \\
\text { organizational issues and events }\end{array}$ & 0.690 & 0.058 & 0.00 \\
\hline $\begin{array}{l}\text { Performance } \\
\text { Management }\end{array}$ & $\begin{array}{l}\text { We maintain a high level of supervision over } \\
\text { our volunteers, and monitor their work } \\
\text { activities heavily. (Reverse-Coded) }\end{array}$ & -0.672 & 0.063 & 0.00 \\
\hline
\end{tabular}


Administrative Characteristics and VRM

\begin{tabular}{|l|l|l|l|l|}
\hline & $\begin{array}{l}\text { Our top volunteer administrator is involved in } \\
\text { organizational planning and strategy activities } \\
\text { at the highest levels of management }\end{array}$ & 0.716 & 0.057 & 0.00 \\
\cline { 2 - 5 } & $\begin{array}{l}\text { Every volunteer has a designated supervisor } \\
\text { (could be one supervisor for multiple } \\
\text { volunteers) }\end{array}$ & 0.504 & 0.076 & 0.00 \\
\cline { 2 - 5 } & $\begin{array}{l}\text { We maintain written conflict resolution or } \\
\text { grievance procedures for volunteers }\end{array}$ & 0.611 & 0.067 & 0.00 \\
\hline & $\begin{array}{l}\text { We have a sole, designated administrator } \\
\text { responsible for overseeing the management of } \\
\text { volunteers agency-wide (e.g., a Director of } \\
\text { Volunteers) }\end{array}$ & 0.464 & 0.081 & 0.00 \\
\hline
\end{tabular}

Note: Standardized coefficients for factor loadings are reported. All factor loadings are significant at $\mathrm{p}<0.001$. 
RUNNING HEAD: Hospital Administrative Characteristics and VRM

Table 2. Means, standardized deviation and correlations

\begin{tabular}{|c|c|c|c|c|c|c|c|c|c|c|c|c|}
\hline Variable & $\mathrm{M}$ & SD & 1 & 2 & 3 & 4 & 5 & 6 & 7 & 8 & 9 & 10 \\
\hline 1. Job design & 3.85 & 0.91 & 1.0 & & & & & & & & & \\
\hline 2. Staffing & 4.18 & 0.68 & $0.89 * *$ & 1.0 & & & & & & & & \\
\hline 3. Orientation & 3.56 & 0.74 & $0.94^{* *}$ & $0.88^{* *}$ & 1.0 & & & & & & & \\
\hline $\begin{array}{l}\text { 4. Performance } \\
\text { Management }\end{array}$ & 3.56 & 0.65 & $0.86^{* *}$ & $0.80^{* *}$ & $0.96^{* *}$ & 1.0 & & & & & & \\
\hline $\begin{array}{l}\text { 5. Size of pd. } \\
\text { volunteer mgmt. staff }\end{array}$ & 1.80 & 1.53 & $0.38 * *$ & $0.31^{* *}$ & $0.27^{* *}$ & $0.27^{* *}$ & 1.0 & & & & & \\
\hline $\begin{array}{l}\text { 6. Location of VRM } \\
\text { function }\end{array}$ & 0.14 & 0.34 & 0.14 & 0.13 & 0.11 & 0.06 & -0.05 & 1.0 & & & & \\
\hline $\begin{array}{l}\text { 7. Volunteer admin.'s } \\
\text { scope of } \\
\text { responsibility }\end{array}$ & 0.64 & 0.49 & $0.26^{*}$ & $0.42 * *$ & $0.23^{*}$ & $0.22 * *$ & $0.23^{*}$ & $0.20^{*}$ & 1.0 & & & \\
\hline 8. Hospital size & 2.28 & 0.38 & $0.40^{* *}$ & $0.47 * *$ & 0.14 & $0.17^{*}$ & $0.40 * *$ & 0.11 & $0.30 * *$ & 1.0 & & \\
\hline $\begin{array}{l}\text { 9. Direct volunteer } \\
\text { services }\end{array}$ & 2.56 & 1.17 & 0.05 & 0.27 & 0.15 & 0.16 & -0.06 & 0.07 & 0.14 & 0.03 & 1.0 & \\
\hline $\begin{array}{l}\text { 10. Indirect volunteer } \\
\text { services }\end{array}$ & 1.86 & 0.98 & -0.06 & -0.03 & -0.12 & -0.17 & 0.01 & $0.22 *$ & -0.09 & 0.12 & $\begin{array}{c}- \\
0.07\end{array}$ & 1.0 \\
\hline
\end{tabular}

Note. $\mathrm{N}=122 .{ }^{*}$ Correlation is significant at the 0.05 level for two tails. ${ }^{* *}$ Correlation is significant at the 0.05 level for two tails. The internal consistency reliability for the VRM scale is 0.83 . 
Table 3. Comparison of measurement models

\begin{tabular}{|c|c|c|c|c|c|c|c|}
\hline Model & Description & $\overline{\chi^{2}}$ & $\overline{\mathrm{df}}$ & $\overline{\Delta \Delta \chi^{2}}$ & RMSEA & CFI & TLI \\
\hline $\begin{array}{l}\text { Model } \\
1\end{array}$ & $\begin{array}{l}10 \text { constructs: VRM dimensions, volunteer manager, foundation } \\
\text { reporting, sole responsibility, type of volunteer service, hospital } \\
\text { size. }\end{array}$ & 267.09 & 228 & & 0.04 & 0.94 & 0.92 \\
\hline $\begin{array}{l}\text { Model } \\
2\end{array}$ & $\begin{array}{l}10 \text { constructs. The correlation between volunteer staff and sole } \\
\text { responsibility was fixed to } 1 \text {. }\end{array}$ & 317.24 & 236 & $50.15^{* *}$ & 0.06 & 0.87 & 0.84 \\
\hline $\begin{array}{l}\text { Model } \\
3\end{array}$ & $\begin{array}{l}10 \text { constructs. The correlation between volunteer staff and } \\
\text { reporting was fixed to } 1 \text {. }\end{array}$ & 318.18 & 236 & $51.09 * *$ & 0.06 & 0.87 & 0.84 \\
\hline $\begin{array}{l}\text { Model } \\
4\end{array}$ & $\begin{array}{l}10 \text { constructs. The correlation between reporting and job title was } \\
\text { fixed to } 1 .\end{array}$ & 290.99 & 236 & $23.90 * *$ & 0.05 & 0.91 & 0.89 \\
\hline $\begin{array}{l}\text { Model } \\
5\end{array}$ & Single construct. All indicators are independent. & 360.14 & 267 & $93.05^{* *}$ & & & \\
\hline
\end{tabular}

\footnotetext{
Note. $\mathrm{df}=$ degrees of freedom; RMSEA=root-mean-square error of approximation; CFI=comparative fit index; TLI=TuckerLewis Index. ${ }^{* *} \mathrm{p}<0.01$.
} 
Figure 1. Results of relationships between antecedents and four-factor VRM practices

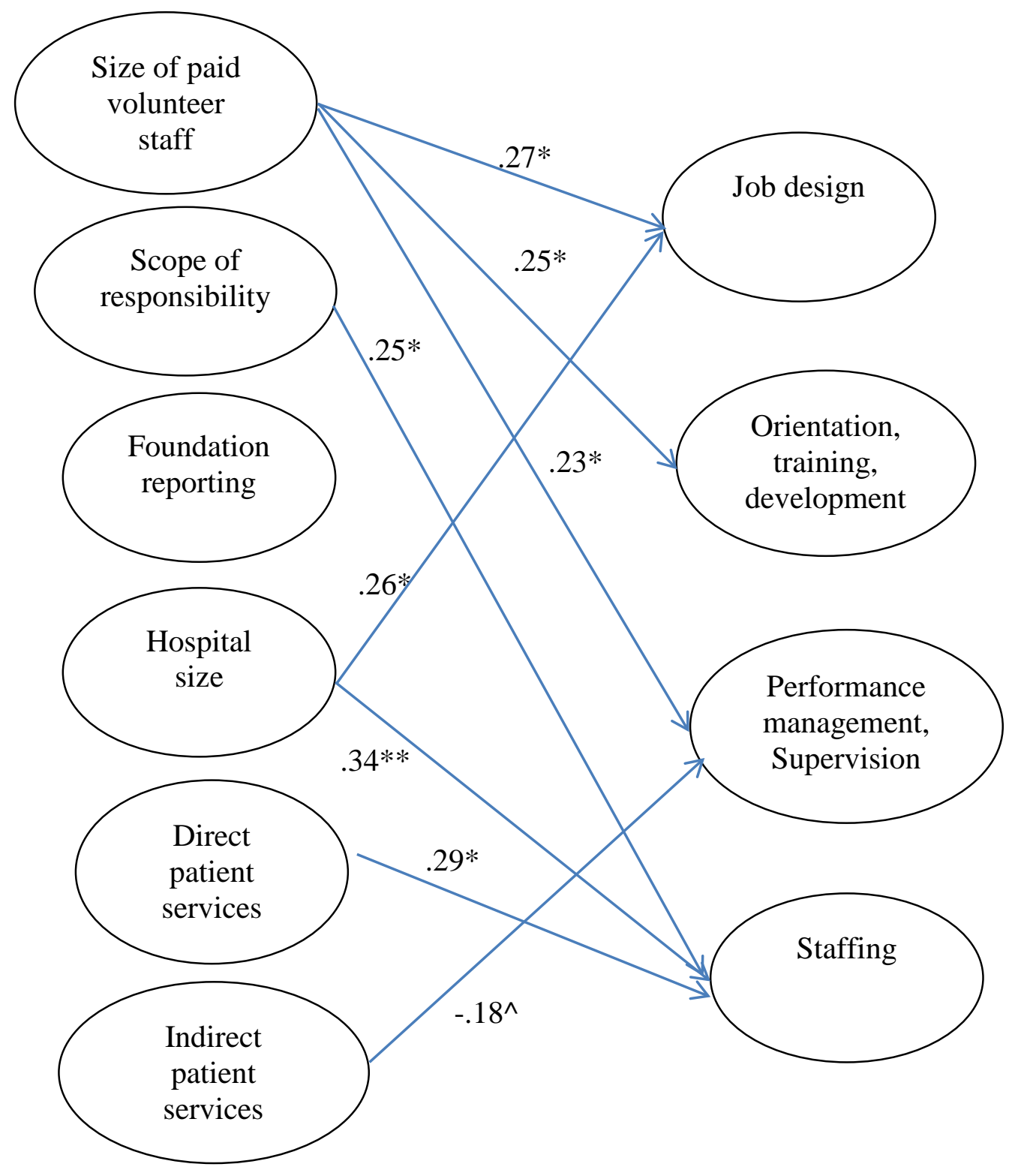

Note: Standardized coefficients for direct effects are reported. Insignificant direct effects are not reported. All factor loadings are significant at $\mathrm{p}<0.001$. ${ }^{*} \mathrm{p}<0.05,{ }^{* *} \mathrm{p}<0.01, \wedge \mathrm{p}<0.10$ (two-tailed). 
${ }^{\text {i }}$ The work of Grinyer \& Yasai-Ardekani (1981) demonstrates a positive relationship between organization size and age, and bureaucracy within organizations. Williamson (1971) suggests that increased bureaucracy may reflect a response to the coordination and control challenges that emerge with increased size. Specifically related to volunteers, Hager \& Brudney (2004) found that larger charities tended to adopt more volunteer management practices than smaller charities. 